\title{
A Pilot Examination of Oxidative Stress in Trichotillomania
}

\author{
Jon E. Grant ${ }^{1 凶}$ and Samuel R. Chamberlain ${ }^{2}$ \\ ${ }^{1}$ Department of Psychiatry \& Behavioral Neuroscience, University of Chicago, Chicago, IL, USA \\ ${ }^{2}$ Department of Psychiatry, University of Cambridge, UK; \& Cambridge and Peterborough NHS Foundation Trust, Cambridge, UK
}

\begin{abstract}
Objective Trichotillomania is a relatively common illness whose neurobiology is poorly understood. One treatment for adult trichotillomania, n-acetyl cysteine (NAC), has antioxidative properties, as well as effects on central glutamatergic transmission. Preclinical models suggest that excessive oxidative stress may be involved in its pathophysiology.

Methods Adults with trichotillomania provided a blood sample for analysis of compounds that may be influenced by oxidative stress [glutathione, angiotensin II, ferritin, iron, glucose, insulin and insulin growth factor 1 (IGF1), and hepcidin]. Participants were examined on symptom severity, disability, and impulsivity. The number of participants with out-of-reference range oxidative stress measures were compared against the null distribution. Correlations between oxidative stress markers and clinical measures were examined.

Results Of 14 participants (mean age 31.2 years; $92.9 \%$ female), $35.7 \%(n=5)$ had total glutathione levels below the reference range ( $\mathrm{p}=$ 0.041). Other oxidative stress measures did not have significant proportions outside the reference ranges. Lower levels of glutathione correlated significantly with higher motor impulsiveness (Barratt Impulsiveness Scale sub-score) $(r=0.97, \mathrm{p}=0.001)$.

Conclusion A third of patients with trichotillomania had low levels of glutathione, and lower levels of glutathione correlated significantly with higher motor impulsiveness. Because NAC is a precursor for cysteine, and cysteine is a rate limiting step for glutathione production, these results may shed light on the mechanisms through which NAC can have beneficial effects for impulsive symptoms. Confirmation of these results requires a suitable larger follow-up study, including an internal normative control group.
\end{abstract}

Psychiatry Investig 2018;15(12):1130-1134

Key Words Trichotillomania, Oxidative stress, Glutathione, Obsessive-compulsive.

\section{INTRODUCTION}

Trichotillomania is a frequently overlooked psychiatric condition characterized by repeatedly pulling out one's own hair. ${ }^{1}$ Despite being documented in the medical literature for almost two centuries, trichotillomania is poorly understood with limited data regarding its pathophysiological basis. ${ }^{2}$ The symptoms in trichotillomania are overt and can be regarded as excessive grooming, a type of maladaptive behavior that is also observable in other species. ${ }^{3}$

Oxidative stress results from the accrual of free radicals within the body. There is emerging data to suggest that oxidative stress may be involved in the pathophysiology of body

Received: April 30, 2018 Revised: August 12, 2018

Accepted: September 7, 2018

$\triangle$ Correspondence: Jon E. Grant, JD, MD, MPH

Department of Psychiatry \& Behavioral Neuroscience, University of Chicago, Pritzker School of Medicine, 5841 S. Maryland Avenue, MC-3077, Chicago 60637, IL, USA

Tel: +1-773-834-1325, Fax: +1-773-834-6761, E-mail: jongrant@uchicago.edu (a) This is an Open Access article distributed under the terms of the Creative Commons Attribution Non-Commercial License (https://creativecommons.org/licenses/bync/4.0) which permits unrestricted non-commercial use, distribution, and reproduction in any medium, provided the original work is properly cited. focused repetitive behaviors such as trichotillomania. For example, in trichotillomania, the amino-acid n-acetyl cysteine (NAC) showed treatment efficacy versus placebo in a randomized, controlled trial, in adults, ${ }^{4}$ although a trial in children was negative. ${ }^{5}$ NAC has also shown efficacy in skin picking disorder, in a randomized controlled trial, in adults. ${ }^{6}$ NAC has effects on glutamatergic transmission in models of addiction ${ }^{7,8}$ but also has antioxidative properties, raising the prospect of two potential underlying treatment mechanisms. ${ }^{9}$ It is not known whether antioxidant, glutamatergic, or both mechanisms were important in mediating positive effects on trichotillomania symptoms in the adult treatment trial. A putative animal model of trichotillomania is the spontaneously occurring 'barbering mouse' model, in which rodents excessively groom their cage mates, and to a lesser extent themselves. ${ }^{10}$ Barbering mice have been reported to have elevated urinary antioxidant capacity, which the authors suggested was consistent with elevated oxidative stress in the animals associated with excessive grooming. ${ }^{11}$

In view of the lack of studies examining compounds that may be influenced by oxidative stress in patients with tricho- 
tillomania, we measured a range of such compounds in a well-characterized sample of patients. We hypothesized that measures of oxidative stress would be abnormal in patients with trichotillomania and significantly correlate with more severe symptoms.

\section{METHODS}

\section{Subjects}

Data from 14 participants with a primary diagnosis of trichotillomania were included in this study. Study procedures were carried out in accordance with the Declaration of Helsinki. The Institutional Review Board at the University of Chicago approved the study (FP059766-01-PR) and subjects provided written informed consent.

All subjects had a current DSM-5 primary diagnosis of trichotillomania. Other inclusion criteria included age 18 to 60 years, the ability to be interviewed in person, and willingness to provide a blood sample. Exclusion criteria included prior/current diagnosis of bipolar disorder, psychosis, or current substance use disorder. Current use of medication was not an exclusion criterion. No participant had previously used or currently was using NAC or any other antioxidant.

\section{Assessments}

Individuals were examined using a semi-structured interview by a board certified psychiatrist, enquiring about any history of mental disorders as well as current diagnostic criteria for trichotillomania. The interview included the Mini International Neuropsychiatric Inventory (MINI), which identifies conditions including mood, anxiety, and eating disorders. ${ }^{12}$

Participants provided a blood sample, and plasma levels of the following compounds that may be influenced by oxidative stress were quantified: glutathione, angiotensin II, ferritin, iron, glucose, insulin and insulin growth factor 1 (IGF1), and hepcidin. Normative reference ranges were supplied by the analyzing laboratory. Choice of compounds was based on the literature examining NAC, grooming in animals, and general stress response. . $^{5,11,13}$

Severity of trichotillomania, psychosocial dysfunction, and impulsivity were assessed with the following measures:

\section{The Massachusetts General Hospital Hair Pulling Scale (MGH-HPS) $)^{14,15}$}

The MGH-HPS is a valid and reliable seven-item, self-report scale that rates urges to pull hair, actual amount of pulling, perceived control over behavior, and distress associated with hair pulling over the preceding seven days.

\section{Sheehan Disability Scale (SDS) ${ }^{16}$}

The SDS is a valid and reliable scale that evaluates psychosocial dysfunction in three domains: work/school, social life, and home/family life.

\section{Barratt Impulsiveness Scale, Version 11 (BIS-11)}

The BIS-11 is a 30 -item measure designed to assess impulsivity across three dimensions: attentional (inability to concentrate), motor (acting without thinking), and non-planning (lack of future orientation). ${ }^{17}$ BIS-11 was collected only for a subset (50\%) of the sample.

\section{Data analysis}

Demographic, clinical, and oxidative stress data are presented in summary form. The number (\%) of oxidative stress markers outside the normative reference ranges were summarized and compared against the null distribution using Fisher's test. Relationships between oxidative stress marker levels and other measures (symptom severity, disability, and motor impulsiveness on the BIS-11) were examined using Spearman's $r$. Statistical significance was defined as $\mathrm{p}<0.05$ two-tailed. We did not adjust for multiple comparisons due to the exploratory nature of this study and sample size.

\section{RESULTS}

The sample comprised 14 participants with trichotillomania [mean age of 31.2 ( \pm SD 8.8 ) years; $92.9 \%$ female]. The mean total score on the MGH-HPS was $16.6( \pm 3.4)$ reflective of moderate symptom severity. Four participants had comorbid depression, and four had an anxiety disorder. One person reported a lifetime diagnosis of attention deficit hyperactivity disorder (ADHD). No other comorbidities were identified. Four patients (28.6\%) were taking one or more psychotropic medications: fluoxetine $20 \mathrm{mg} /$ day; citalopram $20 \mathrm{mg}$ /day; escitalopram $20 \mathrm{mg} /$ day; and fluoxetine $40 \mathrm{mg} /$ day plus Adderall XL $30 \mathrm{mg} /$ day. Levels of oxidative stress markers are summarized in Table 1. The proportion of participants with glutathione levels below the reference range $(35.7 \% ; n=5)$ differed significantly from the distribution expected under the null hypothesis by Fisher's exact test ( $\mathrm{p}=0.041$ ). No other significant differences from the null hypothesis were detected for the other oxidative stress markers, in terms of proportions out of reference range (all $\mathrm{p}>0.10$ ).

Average glutathione levels were 615.5 (131.30) uM in medicated cases, and 652.2 (SD 251.3) uM in the un-medicated cases. Average glutathione levels were $529.0(219.0) \mathrm{uM}$ in people with comorbid depression, and 674.5 (214.9) nM in those without; and were 680.0 (292.4) uM in people with comorbid anxiety disorder and 624.6 (192.1) uM in those without. These 
Table 1. Summary of oxidative stress markers in the trichotillomania sample $(\mathrm{N}=14)$, normative reference ranges, and $\mathrm{N}$ (\%) of subjects with out-of-reference range measures

\begin{tabular}{|c|c|c|c|c|c|c|c|c|}
\hline \multirow{2}{*}{ Oxidativestress measure } & \multirow{2}{*}{ Mean } & \multirow{2}{*}{ SD } & \multirow{2}{*}{ Min } & \multirow{2}{*}{ Max } & \multicolumn{2}{|c|}{ Normative reference range } & \multirow{2}{*}{$\mathrm{N}$ (\%) below ref } & \multirow{2}{*}{$\mathrm{N}(\%)$ above ref } \\
\hline & & & & & Lower & Upper & & \\
\hline Total Glutathione, uM & 640.92 & 216.13 & 311 & 1,026 & 545 & 1,228 & $5(35.7)$ & $0(0)$ \\
\hline Angiotensin II, pg/mL & 26.69 & 16.11 & 3 & 53 & 10 & 60 & $3(21.4)$ & $0(0)$ \\
\hline Ferritin, ng/mL & 42.08 & 22.92 & 5 & 85 & 10 & 220 & $1(7.1)$ & $0(0)$ \\
\hline Iron, $\mathrm{mcg} / \mathrm{dL}$ & 80.18 & 36.04 & 34 & 152 & 40 & 160 & $1(7.1)$ & $0(0)$ \\
\hline Glucose, $\mathrm{mg} / \mathrm{dL}$ & 93.00 & 17.51 & 79 & 146 & 60 & 99 & $0(0)$ & $2(14.3)$ \\
\hline Insulin, $\mathrm{mcU} / \mathrm{mL}$ & 13.73 & 13.86 & 3.8 & 44.1 & 2.6 & 24.7 & $0(0)$ & $3(21.4)$ \\
\hline IGF-1, ng/mL & 126.18 & 50.54 & 22 & 184 & 66 & 303 & $2(14.3)$ & $0(0)$ \\
\hline Hepcidin, $\mathrm{nM}$ & 10.71 & 5.08 & 4 & 18.8 & 4.4 & 47.3 & $1(7.1)$ & $0(0)$ \\
\hline
\end{tabular}

Laboratory analyses done by the University of Chicago, Quest, and Intrinsic LifeSciences. SD: standard deviation

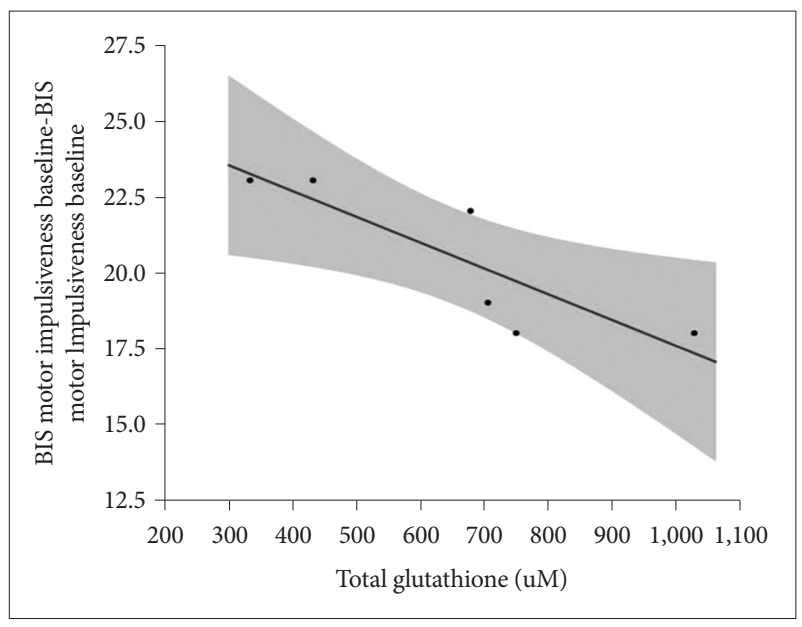

Figure 1. Total glutathione levels correlated significantly and negatively with motor impulsiveness on the Barratt questionnaire (note that Barratt scores were only available for some participants). BIS: Barratt Impulsiveness Scale.

differences between subgroups of patients were not significant (all $\mathrm{p}>0.30$ by Wilcoxon's $\mathrm{Z}$ ).

Lower levels of glutathione correlated highly significantly with higher motor impulsiveness on the BIS-11 in the 6 participants who completed the BIS-11 ( $\mathrm{r}=0.97, \mathrm{p}=0.001)$ (Figure 1). No other correlations between oxidative markers and BIS scores were significant (all $\mathrm{p}>0.05$ ). Oxidative stress markers did not correlate significantly with symptom severity (MGH total scores) or disability (Sheehan Disability scores) (all p $>0.10$ ).

\section{DISCUSSION}

The current study examined a range of blood oxidative stress markers in patients with trichotillomania. The key finding was that a significant proportion of patients had blood levels of glutathione that were below the external normative reference range. Furthermore, in a subset of the sample for whom Barratt Impulsiveness Scale scores were collected, lower levels of glutathione correlated significantly with higher motor impulsivity.

Glutathione is an antioxidant that eliminates free radicals. Oxidative stress pathways are increasingly implicated in a range of mental disorders but have received limited research attention. For example, reduced levels of glutathione have recently been reported in schizophrenia and bipolar disorder. ${ }^{18}$ The current findings may partly explain why $\mathrm{n}$-acetyl cysteine (NAC) shows efficacy in the treatment of trichotillomania and related disorders in some studies. ${ }^{4,6} \mathrm{NAC}$ is a cysteine precursor, and cysteine is the rate limiting step in the body's synthesis of glutathione. ${ }^{19}$ Glutathione in turn is one of the major antioxidants within the body. It is important to note that NAC also has direct effects on the brain's glutamatergic pathways, ${ }^{9}$ and so not all its therapeutic actions necessarily stem from antioxidant effects.

Although there are no prior studies of oxidative stress in trichotillomania, some but not all studies have reported elevated oxidative stress markers in obsessive compulsive disorder (OCD). In an animal model of OCD characterized by stereotypic movements (deer mouse), evidence of deficient glutathione system was found in the cortex selectively. ${ }^{20}$ One study of humans with OCD found lower glutathione levels in the posterior cingulate cortex, ${ }^{21}$ while another study found no significant differences in the total antioxidant status, total oxidant status and oxidative stress index levels between the OCD patients and control group, but serum 8-hydroxideoxiguanosine $(8-\mathrm{OHdG})$ levels were significantly higher in OCD patients than controls. ${ }^{22}$ Taken together with our results, these studies suggest that oxidative stress may be present in a sub-group of people with obsessive-compulsive related disorder such as trichotillomania. Although only a hypothesis, this in turn may also explain why an intervention such as NAC does not work in all people with trichotillomania. One 
could query whether only those with low baseline glutathione levels would respond to NAC. This also possibly explain the negative findings in the study of NAC in children with trichotillomania, ${ }^{5}$ as perhaps only a small percentage of those children had low levels of glutathione.

Although these findings are provocative, several limitations need to be considered. The study did not include an internal control group, and so identification of out-of-reference range measures relied on external norms, which are drawn from other population samples. However, external norms do have the advantage that they are independent of the current study and typically involve large sample sizes. The sample size was relatively small; as such, findings merit confirmation in a larger sample of patients in future. Causation cannot be confirmed in the absence of follow-up studies such as longitudinal examination. The current study was neither designed not powered to address possible effects of co-morbidities and medications on the findings. Interpretation is tempered due to the extremely low sample size for these subgroup analyses. This being an exploratory study, we did not correct for multiple comparisons. We did not measure all possible types of oxidative stress markers. Lastly, BIS-11 scores were only collected from a subset of participants, hence the significant correlation with lower glutathione merits replication in a larger sample, before they can be regarded as firm.

In summary, in this pilot work we found that approximately one-third of adult individuals with trichotillomania had glutathione levels below the normal range; and that lower glutathione was associated with higher motor impulsiveness. Future research should replicate these findings in a larger sample, incorporating a matched internal normal control group, and ideally should dissect the extent to which effects of NAC on brain function and impulsivity are due to glutamatergic versus antioxidant effects (or both). Studies should also examine effects of co-morbidities and various treatments; including whether trichotillomania patients with low baseline levels of glutathione are more likely to experience significant symptom reduction with NAC, which we would hypothesize. The findings may have broader therapeutic relevance for other impulsive and compulsive disorders.

\section{Acknowledgments}

This research did not receive any specific grant from funding agencies in the public, commercial, or not-for-profit sectors. Dr. Jon Grant currently has research grants from the TLC Foundation for Body Focused Repetitive Behaviors, NIAAA, and Takeda Pharmaceuticals. He receives yearly compensation from Springer Publishing for acting as Editor-in-Chief of the Journal of Gambling Studies and has received royalties from Oxford University Press, Johns Hopkins Press, American Psychiatric Publishing, Norton Press, and McGraw Hill. Dr. Samuel Chamberlain's involvement in this project was funded by a Wellcome Trust Clinical Fellowship (110049/Z/15/ Z). Dr. Chamberlain consults for Cambridge Cognition and Shire.

\section{REFERENCES}

1. American Psychiatric Association. Diagnostic and Statistical Manual of Mental Disorders, 5th Ed, Text Revision. Washington D.C.: American Psychiatric Press; 2013.

2. Grant JE, Chamberlain SR. Trichotillomania. Am J Psychiatry 2016; 173: 868-874.

3. Camilla d'Angelo LS, Eagle DM, Grant JE, Fineberg NA, Robbins TW, Chamberlain SR. Animal models of obsessive-compulsive spectrum disorders. CNS Spectr 2014;19:28-49.

4. Grant JE, Odlaug BL, Kim SW. N-acetylcysteine, a glutamate modulator, in the treatment of trichotillomania: a double-blind, placebo-controlled study. Arch Gen Psychiatry 2009;66:756-763.

5. Bloch MH, Panza KE, Grant JE, Pittenger C, Leckman JF. N-Acetylcysteine in the treatment of pediatric trichotillomania: a randomized, double-blind, placebo-controlled add-on trial. J Am Acad Child Adolesc Psychiatry 2013;52:231-240.

6. Grant JE, Chamberlain SR, Redden SA, Leppink EW, Odlaug BL, Kim SW. N-Acetylcysteine in the treatment of excoriation disorder: a randomized clinical trial. JAMA Psychiatry 2016;73:490-496.

7. Kupchik YM, Moussawi K, Tang XC, Wang X, Kalivas BC, Kolokithas $\mathrm{R}$, et al. The effect of $\mathrm{N}$-acetylcysteine in the nucleus accumbens on neurotransmission and relapse to cocaine. Biol Psychiatry 2012;7:978-986.

8. Schmaal L, Veltman DJ, Nederveen A, van den Brink W, Goudriaan AE. N-acetylcysteine normalizes glutamate levels in cocaine-dependent patients: a randomized crossover magnetic resonance spectroscopy study. Neuropsychopharmacology 2012;37:2143-2152.

9. Spencer S, Kalivas PW. Glutamate transport: a new bench to bedside mechanism for treating drug abuse. Int J Neuropsychopharmacol 2017;20:797-812.

10. Garner JP, Weisker SM, Dufour B, Mench JA. Barbering (fur and whisker trimming) by laboratory mice as a model of human trichotillomania and obsessive-compulsive spectrum disorders. Comp Med 2004;54: 216-224.

11. Vieira GLT, Lossie AC, Lay DC Jr, Radcliffe JS, Garner JP. Preventing, treating, and predicting barbering: a fundamental role for biomarkers of oxidative stress in a mouse model of Trichotillomania. PLoS One 2017;12:e0175222.

12. Sheehan DV, Lecrubier Y, Sheehan KH, Amorim P, Janavs J, Weiller E, et al. The Mini-International Neuropsychiatric Interview (M.I.N.I.): the development and validation of a structured diagnostic psychiatric interview for DSM-IV and ICD-10. J Clin Psychiatry 1998;59(Suppl 20): 22-33;quiz 34-57.

13. Amin SN, El-Aidi AA, Zickri MB, Rashed LA, Hassan SS. Hepatoprotective effect of blocking $\mathrm{N}$-methyl-d-aspartate receptors in male albino rats exposed to acute and repeated restraint stress. Can J Physiol Pharmacol 2017;95:721-731.

14. Keuthen NJ, O'Sullivan RL, Ricciardi JN, Shera D, Savage CR, Borgmann AS, et al. The Massachusetts General Hospital (MGH) Hairpulling Scale: 1. development and factor analyses. Psychother Psychosom 1995;64:141-145.

15. O'Sullivan RL, Keuthen NJ, Hayday CF, Ricciardi JN, Buttolph ML, Jenike MA, et al. The Massachusetts General Hospital (MGH) Hairpulling Scale: 2. reliability and validity. Psychother Psychosom 1995;64: 146-148.

16. Sheehan DV, Harnett-Sheehan K, Raj BA. The measurement of disability. Int Clin Psychopharmacol 1996;11(Suppl 3):89-95.

17. Stanford MS, Mathias CW, Dougherty DM, Lake SL, Anderson NE, Patton JH. Fifty years of the Barratt Impulsiveness Scale: an update and review. Pers Individ Dif 2016;47:385-395.

18. Nucifora LG, Tanaka T, Hayes LN, Kim M, Lee BJ, Matsuda T, et al. Reduction of plasma glutathione in psychosis associated with schizophrenia and bipolar disorder in translational psychiatry. Transl Psychiatry 2017;7:e1215.

19. Sansone RA, Sansone LA. Getting a Knack for NAC: N-Acetyl-Cysteine. 
Innov Clin Neurosci 2011:8:10-14

20. Güldenpfennig M, Wolmarans de W, du Preez JL, Stein DJ, Harvey BH. Cortico-striatal oxidative status, dopamine turnover and relation with stereotypy in the deer mouse. Physiol Behav 2011;103:404-411.

21. Brennan BP, Jensen JE, Perriello C, Pope HG Jr, Jenike MA, Hudson JI, et al. Lower posterior congulate cortex glutathione levels in obsessive- compulsive disorder. Biol Psychiatry Cogn Neurosci Neuroimaging 2016;1:116-124.

22. Alici D, Bulbul F, Virit O, Unal A, Altindag A, Alpak G, et al. Evaluation of oxidative metabolism and oxidative DNA damage in patients with obsessive-compulsive disorder. Psychiatry Clin Neurosci 2016;70:109115. 